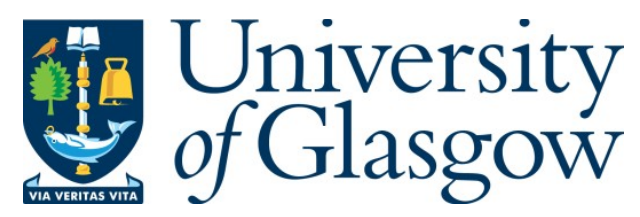

Carter, J. A. (2015) Assertion, uniqueness and epistemic hypocrisy. Synthese, (doi:10.1007/s11229-015-0766-5).

There may be differences between this version and the published version. You are advised to consult the publisher's version if you wish to cite from it.

http://eprints.gla.ac.uk/131956/

Deposited on: 30 November 2016

Enlighten - Research publications by members of the University of Glasgow http://eprints.gla.ac.uk 


\title{
Assertion, Uniqueness and Epistemic Hypocrisy
}

\author{
J. Adam Carter \\ [Forthcoming in Synthese special issue on Truth and Epistemic Norms, eds. \\ J. Dutant, D. Fassio \& A. Meylan.]
}

\begin{abstract}
Pascal Engel (2008) has insisted that a number of notable strategies for rejecting the knowledge norm of assertion are put forward on the basis of the wrong kinds of reasons. A central aim of this paper will be to establish the contrast point: I argue that one very familiar strategy for defending the knowledge norm of assertion - viz., that it is claimed to do better in various respects than its competitors (e.g. the justification and the truth norms)relies on a presupposition that is shown to be ultimately undermotivated. That presupposition is the uniqueness thesis - that there is a unique epistemic rule for assertion, and that such a rule will govern assertions uniformly. In particular, the strategy I shall take here will be to challenge the sufficiency leg of the knowledge norm in a way that at the same time counts against Williamson's (2000) own rationale for the uniqueness thesis. However, rather than to challenge the sufficiency leg of the knowledge norm via the familiar style of 'expert opinion' and, more generally, 'second-hand knowledge' cases (e.g. Lackey (2008)), a strategy that has recently been called into question by Benton (2014), I'll instead advance a very different line of argument against the sufficiency thesis, one which turns on a phenomenon I call epistemic hypocrisy.
\end{abstract}

\section{$\S 1$}

In his excellent paper 'In What Sense is Knowledge The Norm of Assertion?', Pascal Engel (2008) begins by noting three components that, taken together, constitute the Knowledge Account of Assertion: 
Knowledge Account of Assertion (KAA):

(i) There is a norm for the speech act of assertion

(ii) This norm is unique and constitutive of assertion

(iii) This norm is that one must assert that $\mathrm{P}$ only if one knows that $\mathrm{P}$.

Whilst Engel's paper does constitute a kind of defence of the KAA, no where does Engel insist that the KAA is correct; rather, he treads a more cautious line, which is to identify a variety of lines of criticism that have emerged against the KAA and to show how these criticisms are based on different kinds of confusions.

One such confusion has its source in the subtle differences between different articulations of the knowledge norm in (iii). Following Engel, let's call the basic formulation of the knowledge norm ' $\mathrm{KN}$ ':

(KN): One must: assert $p$ only if one knows that $p$

KN is Williamson's $(1996 ; 2000)$ presentation of the norm (and Engel's preferred formulation). But notice that $\mathrm{KN}$ is not equivalent to Moore's 'To assert that $\mathrm{P}$ is to imply that one knows that $\mathrm{P}$ ' nor to Unger's 'To assert that $\mathrm{P}$ is to represent oneself as knowing that $\mathrm{P}^{1}$. Consequently, as Engel has noted, commentators are missing the mark when overlooking that challenging these other articulations of the knowledge norm needn't be successful against the more basic KN.

Another problem Engel locates is the too-common failure to appreciate the sense in which assertion is subject to a norm. In particular, it is sometimes overlooked that it is perfectly compatible with KAA that some bona fide assertions violate the norm, and that other norms or dimensions of evaluation of assertions come into play ${ }^{2}$. Engel at this point makes a number of analogies between assertion and belief. We can believe on the basis of bad reasons ${ }^{3}$, but this point seems orthogonal to the matter of whether belief is subject to a particular norm of correctness

\footnotetext{
${ }^{1} C f$. Pagin (2006) for a criticism.

${ }^{2}$ In particular, Engel thinks that such oversights explain why we some are taken to thinking Jennifer Lackey's (2007) selfless assertion cases - cases where assertions are claimed appropriate in the absence of the satisfaction of the belief condition - are a datum from which it should be concluded that KN and KAA are false.

${ }^{3}$ As Engel puts it, 'There is a clear sense in which a belief which is held for reasons which fall short of being epistemic - for instance a self deceptive belief or one which we aim to have to secure a form of comfort- still counts as a belief, so why could not assertions which are made for reasons which fall short of being epistemic, or which happen to be epistemically weak fail to count as assertions?'
} 
(e.g. truth). As Engel notes: 'The fact that the norm can be in many cases violated, overridden by other norms, or be applied in a very loose and relaxed way in many conversational circumstances does not show that the norm is not in place.'

Although I do not think the KN or KAA are correct, I agree with much of what Engel has to say, and on reflection, this should not be surprising. This is because a major theme in Engel's work over the years has been normativism about belief, and in defending this position, Engel has taken care to show what does and does not count as a legitimate objection to this view ${ }^{4}$. Engel's rationale for defending normativist accounts of belief strikes me as broadly right, and so I am accordingly sympathetic to his drawing attention to ways in which $\mathrm{KN}$ and KAA have been resisted for the wrong reasons. In this contribution my aim will be to register some ways that I think KN and KAA have been accepted for the wrong reasons, and in the process of doing so, I'll attempt to motivate - on the basis of considerations to do with epistemic integrity - some reasons for rejecting it.

\section{$\S 2$}

A starting point to this end will be to examine more carefully an idea operating in the background of (ii) in the KAA. Condition (ii), recall, states that the knowledge norm is unique and constitutive of assertion, as a kind of speech act. A presupposition of an explicit endorsement of condition is that there is one unique epistemic rule for assertion, and that such a rule will govern assertions uniformly ${ }^{5}$. This is, at any rate, obviously the assumption in play in mainstream debates about the norm of assertion; the rules of the game seem to be: some epistemic rule governs assertion; it's plausibly either the truth norm (Weiner 2005), the justification norm (e.g. Douven (2006), Lackey (2007), Kvanvig (2009)), or the knowledge norm. The philosophical objective is to work out which one is right. One would think that the 'uniqueness' assumption is on safe ground, and that at the very least there is some (reasonably compelling) positive rationale

\footnotetext{
${ }^{4}$ See here, for instance, Engel $(2007 ; 2013)$. In doing so, he's taken particular care to make it apparent how being subject to a norm needn't involve any positive avowal to conform to it (which is why desiring to hold false beliefs for pragmatic reasons, for instance, is not a datum that should lead us to think truth is not the standard of correctness for belief.) Cf. Shah $\&$ Velleman (2005).

${ }^{5}$ The claim I shall be interested in here is the view that the knowledge norm is the unique epistemic rule for assertion. This is implied by, but does not imply, the stronger claim formulated in terms of the rule being constitutive of assertion.
} 
for proceeding this way ${ }^{6}$. And even more, given Williamson's classic defence of this norm in his 1996 paper Knowing and Asserting, one would have expected that just such an argument for uniqueness would have come straight from him. Interestingly, as Jessica Brown notes, though 'Williamson provides no argument for the assumption of uniqueness when he introduces it ${ }^{7}$ ' (Brown 2008: 97) Williamson's reasons for accepting uniqueness are rather indirect.

There might be several rules of assertion. There might be one ... Nevertheless, a simple account of assertion would be theoretically satisfying, if it worked $^{8}$." (Williamson 2000: 242 ).

And because Williamson of course finds the knowledge norm to 'work', he thus takes himself to have reason to prefer a unique norm ${ }^{9}$. It is important to be clear here that the kind of support we find from Williamson for uniqueness does not rationalize the presumption we actually find in play in the literature - viz., that if one norm is shown to (for instance) deal with problem cases better than the other two main contenders, then we should endorse that norm as 'the' norm of assertion. This 'last norm standing' approach simply bypasses the matter of whether we should

\footnotetext{
${ }^{6}$ For discussion on this point, see also Carter \& Gordon (2011).

${ }^{7} \mathrm{My}$ italics.

${ }^{8}$ I am taking 'worked' here to mean: is true, or perhaps, is appropriately defensible.

${ }^{9} \mathrm{I}$ am reading Williamson in this passage as regarding establishing the knowledge norm to be a task that is theoretically prior to establishing uniqueness-that is, that establishing uniqueness would be itself be an artefact of establishing the knowledge norm, and in such a way that evidence against the knowledge norm would be evidence against uniqueness. While I think this is the right way to understand what Williamson is saying here, it's also fair to point out that we can imagine a much wider kind of rationale for uniqueness, one on which uniqueness (paired with the knowledge norm) fits naturally within a picture on which knowledge is regarded as playing a range of theoretically explanatory roles characteristic of the knowledge-first approach. And so it's appropriate to evaluate Williamson's remarks here within a wider context-a context where knowledge as a unique epistemic rule governing assertion fits within a wider picture. That being said, reason to think that knowledge is not a unique epistemic rule governing assertion is at the same time evidence against this wider picture. The same point can be made were it to turn out that, for instance, Gerken (2013) is right that no unique epistemic credential warrants practical deliberation. Thus, while it's not charitable to suppose that there is not also a wider philosophical motivation for Williamson's embracing of uniqueness in play in the background, this wider philosophical motivation is less compelling if we have reason to doubt the knowledge norm. Thanks to an anonymous referee at Synthese for requesting further elaboration on this point.
} 
be looking for just one norm in the first place. For reasons of simplicity, Williamson is probably right that a unique norm would be ceteris paribus more theoretically satisfying. But even if the KN can be argued to do better than weaker norms, such as Weiner's truth norm and the Lackey/Douven/Kvanvig justification norm, this falls short of a compelling reason to accept the uniqueness assumption.

\section{$\S 3$}

Engel and Williamson might point out here that if the $\mathrm{KN}$ is not the unique norm of assertion, it is not because one of the weaker norms is 'also' a norm of assertion. Engel quotes Williamson here, in response to cases of lying and selfless assertion (where assertion would appear proper despite a lack of knowledge), as remarking that:

Such cases do not show that the knowledge rule is not the rule of assertion. They merely show that it can be overridden by other norms not specific to assertion. The other norms do not give me warrant to assert $\mathrm{p}$, for to have such warrant is to satisfy the rule of assertion" (Williamson 2000: 256), cited also in Engel (2004), my italics.

This reply is telling in two ways. Firstly, it suggests a kind of cookbook recipe for explaining away challenges to $\mathrm{KN}$ on the basis of being 'too strong' an epistemic norm. The recipe is to locate a non-epistemic norm satisfied in such cases (e.g. perhaps a Gricean norm) and then to insist that the apparent propriety of the assertion is a matter of satisfying that norm, all whilst maintaining that 'the rule' would have been satisfied only were one to have knowledge. Setting aside questionbegging-worries (vis-a-vis the uniqueness assumption), notice that this reply reveals also the thought that whatever epistemic norm it is that uniquely governs assertion, it is one that would be satisfied were one to satisfy 'the' rule, which is knowledge. This is tantamount to an endorsement of knowledge as a sufficient epistemic credential for 'whatever the assertion rule is ${ }^{10}$.

\footnotetext{
${ }^{10} \mathrm{An}$ anonymous referee raises the question of whether it would be open for Williamson to embrace a no epistemic status variation on the sufficiency thesis, in conjunction the view that knowledge is always necessary for epistemically appropriate assertion. On this envisioned view, Williamson would be embracing the necessity leg of the knowledge norm while denying that there is any epistemic status such that that status is sufficient as an epistemic credential to warrant assertion. While I've argued elsewhere (2011) that that option's not available to Williamson, I won't rely
} 
As I've argued elsewhere ${ }^{11}$, the idea that knowledge is sufficient as an epistemic credential ${ }^{12}$ is something that operates in the background not only in the replies of proponents of $\mathrm{KN}$ in response to charges that the norm is too strong, but also in the thinking of those who endorse epistemically weaker unique assertion norms ${ }^{13}$. This is revealed in modus operandi of asking 'how much epistemic strength' is needed to warrant assertion? Given that knowledge is about as much as one could hope for, both critics and proponents of the KN and KAA implicitly maintain that 'the epistemic rule' is satisfied if one knows what one asserts ${ }^{14}$.

on this point here. Rather, I think it's worth pointing out why I think embracing a 'no epistemic status' view (with respect to the sufficiency leg) would be an unprincipled position for any defender of the knowledge norm's necessity leg, even if the no epistemic status view were independently plausible. The reasoning here is as follows. Firstly, unless we want to embrace an error-theory according to which all assertions are epistemically impermissible, we should accept it as a datum that assertions are often epistemically permissible. The best explanation for why this datum, along with the no-epistemic-status view of the sufficiency leg would be jointly true would be epistemic norm pluralism, the view that when assertion is epistemically permissible, this will be in virtue of different epistemic statuses being satisfied in different cases. But embracing epistemic norm pluralism for the sufficiency leg and the knowledge norm for the necessity leg is a theoretically unstable pairing. All things equal, we should expect a pluralist about the sufficiency leg to be a pluralist about the necessity leg. More weakly, there is additional explanatory burden on one who is a pluralist about the sufficiency leg while denying pluralism about the necessity leg.

${ }^{11}$ See Carter \& Gordon (2011).

${ }^{12}$ The term 'epistemic credential' is Lackey's (2012).

${ }^{13}$ This is not to say that there has not been criticism of the sufficiency thesis. See fn. 16 .

${ }^{14}$ See, however, Benton (2014) for some resistance to this point. I don't have the space to rehearse my previous argument to this effect here, but want to offer two clarificatory comments. Firstly, I don't regard a commitment to the necessity leg of the knowledge norm to entail a commitment to the sufficiency leg. That is too strong: however, what I've suggested before is that a commitment to the sufficiency leg is clearly implicit in defences of the knowledge account of assertion, where the necessity leg is primarily what is at issue. I am taking it that if the sufficiency thesis is false, then this is evidence against the knowledge account of assertion, even if it does not entail the falsity of the necessity leg of this account. Secondly, the hypocrisy-based argument I outlined in what follows, here goes through in a qualified way even if this is false-viz even if we can glean nothing more from evidence against KNA-Suff than that KNA-Suff is false-as (and as Benton 2014 highlights) whether this sufficiency leg is true has enjoyed considerable debate recently outwith the wider question of the knowledge account of assertion, more generally. 


\section{$\S 4$}

Reason to resist the sufficiency thesis vis-a-vis knowledge is at the same time reason to doubt that the KN 'works'. After all, if sufficiency fails, then sometimes there is a different epistemic rule in play, one not satisfied just by having knowledge. Recall that (a la Williamson) it was because KN 'worked' that we were entitled to think that a unique rule governs assertion ${ }^{15}$. If the sufficiency thesis fails, then, there is a kind of undercutting defeater for the initial reason for Williamons ever offered for accepting uniqueness in the first place. In short, (i) if uniqueness is wrong, then so is a popular rationale for accepting $\mathrm{KN}$; and (ii) if the sufficiency thesis is wrong, then all the worse for 'uniqueness'.

Why think the sufficiency thesis mistaken? One of the most popular recent strategies ${ }^{16}$ for challenging sufficiency appeals to an insight Jennifer Lackey (2012) has termed isolated second-hand knowledge, and in particular, to rely on cases where expert testimony exhibits the following feature: an expert plausibly knows some proposition $p$, asserts $p$, and yet that expert's assertion that $p$ is epistemically criticisable because in asserting $p$ the expert represents herself has having better than merely 'second hand' knowledge.

Consider, as a representative example of such a case, the following, offered by Lackey $(2011,253)$ :

DOCTOR: Matilda is an oncologist at a teaching hospital who has been diagnosing and treating various kinds of cancers for the past fifteen years. One of her patients, Derek, was recently referred to her office because he has been experiencing intense abdominal pain for a couple of weeks. Matilda requested an ultrasound and MRI, but the results of the tests arrived on her day off; consequently, all the relevant data were reviewed by Nancy, a competent medical student in oncology training at her hospital. Being able to confer for only a very brief period of time prior to Derek's appointment today, Nancy communicated to Matilda simply that her diagnosis is pancreatic cancer, without offering any of the details of the test results or the reasons underlying her conclusion. Shortly thereafter, Matilda had her appointment with Derek, where she truly asserts to him purely on the basis of Nancy's reli-

\footnotetext{
${ }^{15}$ See footnote 8 for elaboration on this point, and some qualification.

${ }^{16}$ See, for example, along with Lackey (2012, 2014), Coffman (2011), McKinnon (2012), Gerken (2014), Carter \& Gordon (2011). Cf. Benton (2014).
} 
able testimony, 'I am very sorry to tell you this, but you have pancreatic cancer.' (Lackey 2011, 253)

This case looks initially very problematic for the sufficiency leg of the knowledge norm. After all, deny that Matilda knows on the basis of Nancy's testimony, and we trend toward skepticism. Yet, there is a strong intuition to regard Matilda's testimony as in some way epistemically deficient.

I've been among those who have found this style of argument persuasive $^{17}$; in short, what I regarded as the most plausible diagnosis of DOCTOR is that Matilda, qua expert, lacks a kind of explanatory understanding which, in this context, constitutes the appropriate kind of epistemic credential to warrant assertion ${ }^{18}$. This may well be right, though recent work by Matthew Benton (2014) suggests that intuitions in these cases could very plausibly rest on a number of confusions. Consider, for instance, some questions Benton (2014) raises:

... do we expect of experts that when speaking as experts they are giving their own expert opinion which has been formed by engaging their expertise in a first-hand manner with the relevant evidence or data? (If we do, is that expectation reasonable?) Do we expect that experts always have an obligation to explain to a non-expert what is behind the formation of their opinion? Are there any conditions under which experts may defer to the authority of other experts for a second-hand opinion, or a communal consensus, for the purpose of providing timely efficient testimony to non-experts? Such questions await further investigation.

Benton's questions strike me as worrying for the strategy against the sufficiency thesis which I've previously pursued. In short, I'm not sure how to answer these questions, and in light of this, I am less confident about the evidential weight of this kind of case. To be clear, I don't regard a lack of a principled answer on this score to rebut the standard Lackey-style line that DOCTOR counts against the sufficiency thesis. Rather, I regard Benton as having posed a kind of undercutting defeater, at least, for the original line of thinking according to which we move from intuitions about DOCTOR to the conclusion that the sufficiency thesis is

\footnotetext{
${ }^{17}$ Carter \& Gordon (2011).

${ }^{18} C f$. Lackey (2013) for a criticism of the view that understanding is what's lacking in these cases.
} 
false. Rather than to try to defeat this undercutting defeater by answering Benton's questions and then on the basis of these answers sharpening how a diagnosis of DOCTOR-style cases should go, I want to try to take things in a different direction - that is, to challenge sufficiency in a way that doesn't rely on DOCTOR or any such cases in the neighbourhood.

\section{$\S 5$}

Consider now the following pair of cases:

ADOPTION-1: Irene has always wanted a Siberian Husky, though she realises that adopting one could be dangerous, given that she has a child in the house. Her friend, Nina, hears from the Husky adoption agency that a 2-year old female, "Nymeria," is safe to be around children, and she tells this to Irene. Irene adopts Nymeria on Nina's word. Incidentally, Nina happens to want to adopt a Husky as well, and is similarly hoping to find one that is safe to be around children. Given her epistemic grounds for believing Nymeria is safe to be around children, Nina would have adopted Nymeria (but didn't in this case only because she couldn't afford the adoption fee).

ADOPTION-2: Irene has always wanted a Siberian Husky, though she realises that adopting one could be dangerous, given that she has a child in the house. Her friend, Nina, hears from the Husky adoption agency that a 2-year old female, "Nymeria," is safe to be around children, and asserts this to Irene. Irene adopts Nymeria on Nina's word, taking Nina to be honest. Incidentally, Nina (who in this case, can afford the fee) happens to want to adopt a Husky as well, and is similarly hoping to find one that is safe to be around children. Although the testimony from the Husky agency was good enough to epistemically justify Nina's belief that Nymeria was safe around kids, it wasn't (by Nina's own lights) good enough for Nina herself to act on - she would only have adopted a Husky if she had more conclusive evidence that it was safe to be around children.

I want to now make some initial observations, which I'll later flesh out in more detail. Firstly, Nina's assertion in ADOPTION-2 seems 
criticisable in a way that her assertion in ADOPTION-1 is not. Just as, in Lackey's DOCTOR, it's prima facie plausible to suppose that Derek rightly expects that Matilda's testimony has a certain property beyond just that that it's something Matilda knows - viz., that she knows it on the basis of a certain kind of evidence - it's likewise prima facie plausible to suppose that Irina expects Nina's testimony to have a certain property beyond just that Nina knows it, viz., that if Nina were in Irene's shoes, Nina would take what she asserts as a premise in her own practical reasoning. Were Irene to learn subsequently that Nina would not have done so - viz., that Nina regarded her own epistemic situation to be good enough for Irene to act on but not good enough for Nina herself to act on-Irene will find herself in a position not unlike Derek: her expectation about an epistemically relevant feature of the assertion will have not been met.

Lackey uses the term 'quality' to refer to something about Matilda's assertion which she thinks Derek would rightly regard to be lacking, despite Matilda's knowing what she asserts. Specifically, for Lackey, Matilda's assertion lacked a certain quality it would have had only if Matilda had a particular kind of evidence she lacked. In ADOPTION2, Nina's assertion lacked a certain quality it would have had only if Nina would have also herself been willing to rely on the content of the assertion.

I want to now sketch out, for illustrative purposes, how a case against the sufficiency leg of justification account of assertion (JNA-Suff) would work, drawing from the kind of insight I've just alluded to - which I'll continue to sharpen - and then I'll explain why I take the case I pose against JNA-Suff to be generalisable, as an argument-type, against the sufficiency leg of the KNA (hereafter, KNA-Suff), and in a way that (unlike Lackey's case) does not rely on any intuitions about expert roles of the kind Benton (2014) found objectionably unclear. This will involve putting some pieces together.

To generate the conclusion that the JNA-Suff is incorrect, begin by assuming (for reductio) what the JNA claims: that one is properly epistemically positioned to assert $p$ provided one is epistemically justified in believing that $p$. Here's the first premise of the argument:

(1) In ADOPTION-1, Nina's grounds for her assertion "Nymeria is safe to be around children," satisfy the justification norm of assertion (JNA).

Supposing that the Husky agency is especially reliable in its assessment of dogs' characters, and that Nina knows this, the testimony she 
receives from the agency representative provides her with excellent evidential grounds for the belief she asserts. Accordingly, it is, to use Douven's (2008) terminology, 'rationally credible ${ }^{19}$ ' to Nina to believe that Nymeria is safe to be around children; similarly, on Lackey's (2008) view, it is reasonable for Nina to believe the proposition she asserts ${ }^{20}$, and - by Kvanvig's (2010) ${ }^{21}$ lights - Nina's total perspective recommends her belief that the Nymeria is safe to be around children. So if JNA-Suff is right, then Nina's assertion is epistemically beyond reproach. Now, for the second premise:

(2) If Nina's grounds for her assertion "Nymeria is safe to be around children," satisfy the JNA in ADOPTION-1, they will also satisfy the JNA in ADOPTION-2.

The evidential grounds are, after all, exactly the same in the two cases. Accordingly, JNA-Suff implies that if Nina's assertion is epistemically permissible in ADOPTION-1, it is also epistemically permissible in ADOPTION-2. A knee-jerk response here might be to suppose that this kind of thinking underwriting (2) simply assumes invariantism. But this is not so; (2) holds even if we are inclined toward something like justification contextualism, given that the relevant practical stakes for Nina, in asserting what she does to Irene, are the same across the two cases, ADOPTION-1 and ADOPTION-2 22 . In both cases, she knows Irene wants to adopt a non-dangerous Husky and tells her what she does on evidence that itself does not vary across the two cases.

\footnotetext{
${ }^{19}$ According to Douven's (2008) preferred version of the justification norm, which he calls the Rational Credibility Norm of Assertion, one is properly epistemically positioned to assert only what is rationally credible to one.

${ }^{20}$ On Lackey's (2007) construal of the justification norm, which she calls the Reasonable to Believe Norm of Assertion, one is properly epistemically positioned to assert that p only if (i) it is reasonable to one to believe that p, and (ii) if one asserted that $\mathrm{p}$, one would assert that $\mathrm{p}$ at least in part because it is reasonable for one to believe that $\mathrm{p}$.

${ }^{21}$ Kvanvig's (2010) preferred account of the justification norm makes reference to one's total perspective providing one with good reasons or justification for $\mathrm{p}$.

${ }^{22}$ I don't want to suggest that this premise holds for all varieties of context sensitivity, just standard ones. For example, a relativist (e.g. MacFarlane 2005, 2014) would have comparably more scope to resist (2). However, even if justification were assessment-sensitive along the model MacFarlane develops in defending a truthrelative semantics for 'knows', it's not obvious that relativists would be inclined to deny (2). After all, if the case-pair is evaluated relative to the same context of assessment, we can easily envision the relativist agreeing with (2).
} 
Of course, the premise doing the heavy lifting, and which I'll motivate in more detail in the next section, in generating the result that we should reject the sufficiency leg of the JNA is (3):

(3) In ADOPTION-2, Nina's assertion is epistemically criticisable (e.g. it does not pass scrutiny from an epistemic point of view)

which, with (1) and (2), along with the definition of JNA-Suff, implies:

(4) Therefore, the sufficiency leg of JNA is false (from JNASuff, 1,2,3).

In defending (3), what I want to contend - and defend further in the next section - is that, in ADOPTION-2, (unlike in ADOPTION-1) Nina's assertion is in fact epistemically criticisable; holding fixed the practical facts of the context of her assertion, the assertion would have been epistemically permissible only if she had better epistemic grounds than she did when asserting C. ${ }^{23}$ More specifically, what I shall suggest is that in ADOPTION-2, if Nina had better epistemic grounds than she didindeed, grounds good enough that she would have acted on them-this would vitiate (completely) any intuitive basis for criticising the assertion; the assertion would have been as unproblematic as the assertion in ADOPTION-1. And an explanation I shall outline on this score ultimately reveals a recipe for challenging a more secure view than the sufficiency leg of the justification norm, viz., the sufficiency leg of the knowledge norm.

\footnotetext{
${ }^{23}$ If (simply) an improvement in one's epistemic grounds is all that would be needed to separate a defective assertion from a permissible assertion, then it's plausible to think this assertion is epistemically criticisable, rather than criticisable in some other way. After all, it's specifically the epistemic grounds that make the difference. Also, as a point of clarification: it would be a mistake to think that Nina, in ADOPTION2 , is merely violating some sort of pragmatic, Gricean norm, according to which one 'shouldn't assert hypocritically' even while passing scrutiny from an epistemic point of view. Firstly, the account of epistemic defectiveness just proposed (i.e. that an assertion is epistemically criticisable if all that separates it from being permissible is need for improved epistemic grounds) implies that Nina's assertion is epistemically defective even if it violates some other Gricean norm prohibiting hypocrisy; the two needn't be mutually exclusive. Secondly, a Gricean norm according to which assertions shouldn't be hypocritical would more plausibly be construed as a non-epistemic norm that is violated only when one's explicitly asserted prescription or evaluation involves a double-standard.
} 


\section{$\S 6$}

Again, using JNA as a toy example before we resituate the point with respect to KNA: that Nina's assertion seems epistemically criticisable in the former, but not the latter case, would be inexplicable on the assumption that JNA-Suff is true; Nina satisfies the justification norm in ADOPTION-2 no less than she does in ADOPTION-1. JNA-Suff predicts the assertions will be equally epistemically permissible. Accordingly, then, an account of epistemic impropriety in ADOPTION-2 - and hence a defence of premise (3) against the JNA-Suff-will involve (as a premise) some commitment to a different kind of epistemic norm than JNA. But what would it be?

I think we can make some inroads here by contrasting two notions: epistemic hypocrisy and epistemic integrity. Define epistemic hypocrisy as follows:

Epistemic hypocrisy: An assertor A's assertion p exhibits epistemic hypocrisy if (i) A asserts p to B; (ii) A wouldn't use $\mathrm{p}$ as a premise in A's own practical deliberation; (iii) A expects B to rely on what A asserts in B's practical deliberation; and (iv) A would use p in A's practical deliberations only were A's epistemic support for p better than it is when A asserts $\mathrm{p}$ to B.

Discovering that you are the recipient of epistemically hypocritical testimony from an asserter is much like learning that the accountant that someone has recommended to you is not one that that individual trusts enough to use herself. Upon finding out (say, by hacking into your accountant-recommender's e-mail) that the recommender did not have enough confidence in the competency of the accountant she's just recommended to you to use, to rely on herself, you will be right to be miffed. An entirely reasonable expectation about a certain quality of the assertion has not been met. That the criticisability of the assertion is epistemic, not merely practical, can be supported with reference to the point that your interlocutor would have relied on the accountant she just recommended to you, only were your interlocutor to have had better epistemic grounds to regard her as trustworthy.

The expectation that was not met in the case of the recommendation of the accountant was a certain kind of epistemic integrity, a quality your 'friend"s testimony lacked, regardless of whether, say, your friend knew the accountant was reliable. You immediately withdraw your criticism, 
of course, if you learn that the e-mail contained a typo, and that your friend was in fact willing to use the accountant she just recommended to you on the basis of the epistemic support she had in recommending that accountant to you. The 'antidote' to epistemic hypocrisy is epistemic integrity.

Epistemic integrity (as well as epistemic hypocrisy, as exhibited by Nina in the latter case) is a function not only of the epistemic grounds one has simpliciter, but also of the grounds one has relative to one's disposition to act on these same grounds. We can make sense of the epistemic impropriety of Nina's assertion once we recognise (contrary to what is assumed by the orthodox norms on offer) that the propriety of her assertion is subject to a distinctively social-epistemic dimension of epistemic evaluation, a dimension of evaluation that looks beyond just what the individual's grounds are for the assertion she has. A norm the satisfaction of which will not be fixed just by facts about the epistemic standing occupied by the asserter, but also only once relational facts about that epistemic standing are fixed, is:

Epistemic Integrity Norm (EIN): One must: assert p only if one accepts $\mathrm{p}$ on the basis of epistemic grounds on which one would act; or, alternatively: one must: assert $\mathrm{p}$ only if one accepts $\mathrm{p}$ on the basis of epistemic grounds on which one would take $\mathrm{p}$ as a premise in S's practical reasoning.

If EIN (or something near enough to it) is right, we can easily derive an explanation for the epistemic impropriety of Nina's assertion, so long as we are willing to take on board a plausible principle about the function of assertion, which, as Jessica Brown (2012) puts it, is that one of the distinctive functions of assertion is to entitle hearers to rely on the asserted proposition in their practical deliberations (e.g. Brandom 1983; Milne 2009). Call this (as she does) the licensing view of the function of assertion $^{24}$.

EIN, supplemented with the licensing view of the function of assertion, generates a neat explanation for why Nina's assertion in ADOPTION2 is epistemically impermissible, even though permissible in ADOPTION1 , and all this even though the epistemic grounds Nina has (assessed independently of their connection to Nina's disposition to act) do not vary

\footnotetext{
${ }^{24}$ As Brandom (1983: 640) puts the idea: "The asserted sentence warrants the audience to assert just those sentences which may appropriately be inferred from the original claim." Cf. Brown (2012: 145) for a more detailed discussion of the licensing view, and its connection to epistemic norms of assertion.
} 
across these cases. And so the argument against JNA goes through ${ }^{25}$.

Before examining the EIN more closely (and defending it a potential line of objection), I want to show why the epistemic impropriety in ADOPTION-2 can't be accounted for by the knowledge account of assertion. In short, this is because argument I've sketched against JNA generalises to show the inadequacy of the knowledge norm, via its sufficiency leg. Here's the generalisation recipe ${ }^{26}$ :

(i) Construct a variant of the ADOPTION pair of cases but where the epistemic grounds in Case 1 and 2 are stronger than they are in ADOPTION, strong enough so as to plausibly qualify as knowledge, though not maximally strong in order to leave room for a potential improvement in one's epistemic position vis-a-vis the target proposition. ${ }^{27}$

(ii) In Case 1, S asserts $\mathrm{p}$ on the basis of his knowledge that $\mathrm{p}$, and would (in the relevant counterfactual situations) act on $\mathrm{p}$ (or, alternatively, take $\mathrm{p}$ as a premise in S's practical reasoning). Build Case 2 to mirror Case 1, and so in Case 2, $\mathrm{S}$ knows that $\mathrm{p}$, but in Case $2, \mathrm{~S}$ is not disposed to act on $\mathrm{p}$, and would be disposed to do so only if S's epistemic grounds were comparatively stronger. ${ }^{28}$

\footnotetext{
${ }^{25}$ I want to briefly comment on the connection between EIN and a related epistemic norm that has been defended by Jim Stone (2007) and which also links epistemically appropriate assertion with action. On Stone's account, S is entitled to assert p when $\mathrm{S}$ believes $\mathrm{p}$ on the basis of evidence that makes believing $\mathrm{p}$ reasonable, so much so that, under the circumstances, it's reasonable to act on p. (Stone 2008: 19). I think Stone's account has merits that the traditional norms lack, but unlike EIN, Stone's account is going to fall in step with the knowledge, justification and truth norms in counting epistemically hypocritical assertions as free from epistemic scrutiny. After all, one might not actually be disposed to act on the epistemic grounds one has even if it would be reasonable (given these grounds) for her to do so.

${ }^{26}$ It should be clear how the same cookbook recipe can be generated against the truth norm.

${ }^{27}$ This should be unobjectionable to epistemologists who accept even weak versions of fallibilism.

${ }^{28}$ Even for philosophers who reject fallibilism, the argument I've adduced here against the KNA should go through. This is because all that is needed to generate a case where one satisfies the KNA but nonetheless asserts in a way that is epistemically criticisable is for one to be unwilling to act on one's epistemic grounds because she doesn't take them to be sufficient to warrant (her own) action. So long as she wouldn't act on her knowledge (in part because she judges her epistemic grounds to be epistemically inadequate), and yet asserts her item of knowledge which she believes to be unactionable for her, her assertion counts as epistemically defective (by EIN) even though satisfying the KNA.
} 
(iii) Point out that the impropriety in Case 2 is epistemic (after all, in Case 2, the assertion would have been permissible were the epistemic grounds strong enough that $\mathrm{S}$ would act on them) and that it can't be explained by appeal to the KNA, which $\mathrm{S}$ satisfies in both Case 1 and Case $2^{29}$.

\section{$\S 7$}

Question: do I want to say that EIN simply is the unique epistemic norm of assertion, and hence, assertion passes scrutiny from an epistemic point of view just in case it passes scrutiny from the kind of social-epistemic perspective of evaluation captured by EIN? Answer: no.

The very feature of the EIN which makes it sensitive to epistemically criticisable epistemic hypocrisy (by way of its sensitivity to the grounds one would act on) is a feature that appears to open it up to counterexample, in so far as EIN is construed as the epistemic norm for assertion. Consider the following case:

JOE SIX PACK: Joe Six Pack and his friend, Lionel, are going to a party, where Joe informs him that there will be a keg-stand competition. Lionel seems reticent to participate;

\footnotetext{
${ }^{29}$ It will be helpful here to comment on the relationship between EIN and the knowledge action norm, as defended by among others Hawthorne (2004), Fantl \& McGrath (2002) and Hawthorne \& Stanley (2008). As Hawthorne (2004, 30) puts the idea: '...it is acceptable to use the premise that $\mathrm{p}$ in one's [practical] deliberations if one knows it and . . . unacceptable to use the premise that $\mathrm{p}$ in one's practical reasoning if one doesn't know it.' Given that the EIN, in an obvious respect, makes action relevant to whether one counts as satisfying a plausible epistemic norm on assertion, and given that the knowledge action norm directly connects action and knowledge, one might wonder whether a proponent of a knowledge action norm gets something like EIN for free. There are two reasons why this is not so. Firstly, something like Cappelen's (2011) 'no assertion' view remains a theoretical possibility for one who embraces a knowledge action norm; that is, one might accept Hawthorne's claim in the quoted passage while following Cappelen and denying that it is, as he puts it, 'theoretically useful to single out a subset of sayings as assertions.' Given this theoretical possibility, it's a mistake to think that EIN, or more generally any particular epistemic norm governing assertion, is entailed by a knowledge account of action. Even more though, it's not clear that, for one who does opt for some epistemic norm governing assertion, that embracing the knowledge action norm obviously recommends EIN, a result which further suggests the views are theoretically orthogonal. The Joe Six Pack case, for example, is one that satisfies the EIN but which violates the knowledge-action norm. Thanks to an anonymous referee at Synthese for requesting further discussion on this point.
} 
he mentions to Joe that he has been prescribed anticoagulants for his blood clots and is currently taking Warfarin ${ }^{30}$. Jovially, Joe tells Lionel that his grandfather takes Warfarin and drinks all the time; he asserts: "It's perfectly safe to drink alcohol and take Warfarin--if I had blood clots and were on Warfarin, I'd drink."

Joe's assertion is epistemically criticisable, even though Joe satisfies EIN. Is this a problem for EIN? It certainly would be, if the uniqueness thesis were antecedently established. But the very cases that motivate a need for EIN, over and above either the justification or knowledge norms, count against the original basis Williamson offers us for accepting uniqueness in the first place. Where does that leave us? I think that where that leaves us is a spot where we should be more prepared to think that the epistemic rule governing assertion will not always be uniform. (This is tantamount to thinking outside the box of the uniqueness assumption). Recent work by Gerken (2013) has moved in this direction, and in particular, in the direction of supposing different epistemic rules will be in play in different contexts ${ }^{31}$. This is messier than Williamson wanteduniqueness is much cleaner - and it would be preferable, and at minimum more elegant, if one unique norm 'worked.' But to the extent that epistemically hypocritical assertions are as I've suggested here epistemically defective ones, it's hard to see just how one would, the knowledge norm, or otherwise ${ }^{32}$

\footnotetext{
${ }^{30}$ Warfarin thins the blood, which prevents its ability to clot. Significant alcohol consumption enhances Warfarin's effect.

${ }^{31} \mathrm{Cf}$. Turri (2014) who suggests that the uniqueness assumption may be rejected in favour of what he calls a pluralist axiological knowledge account of assertion (which is nevertheless, a knowledge norm of assertion). I am directing the challenge for sufficiency, as developed here, against what Turri himself rejects under the description of the simple version of the knowledge norm $(2014,558)$, which is also the standard way of thinking of the knowledge norm. I'll remain agnostic for the present purposes whether epistemic hypocrisy cases can support counterexamples to the more complex pluralist axiological knowledge account of assertion Turri defends. Thanks to an anonymous referee at Synthese for raising this point.

${ }^{32}$ It is a great pleasure to contribute to Pascal Engel's Festschrift on the occasion of his $60^{\text {th }}$ birthday. One particular topic I've had the opportunity to discuss with him in some detail is assertion, and in particular, assertoric norms, and so naturally, this is a topic I thought would be most fitting to explore here. Thanks also to Julien Dutant, Davide Fassio and Anne Meylan and two anonymous referees at Synthese, and also to Emma C. Gordon for helpful conversation. An ancestor paper to this one-'Engel on Knowledge Account of Assertion'-appeared in Liber Amicorum Pascal Engel, eds. J. Dutant, D. Fassio \& A. Meylan, University of Geneva, 158-168.
} 


\section{References}

Benton, M. (2014). 'Expert Opinion and Second-Hand Knowledge.' Philosophy and Phenomenological Research.

Brandom, R. (1983). 'Asserting', Nous 17.4 (1983): 637-650.

Brown, J. (2008a) 'The Knowledge Norm for Assertion', Philosophical Issues, 18, Interdisciplinary Core Philosophy, 2008.

Brown, J. (2008b). 'Knowledge and Practical Reason', Philosophy Compass, 3.6, 1135-1152.

Carter, J.A. \& Gordon, E.C. (2011). 'Norms of Assertion: The Quantity and Quality of Epistemic Support'. Philosophia, 39(4), 615-635.

Cappelen, H. (2011). 'Against Assertion'. In Jessica Brown \& Herman Cappelen (eds.), Assertion: New Philosophical Essays. Oxford University Press.

Douven, I. (2008) 'Assertion, Knowledge and Rational Credibility', Philosophical Review 2006 115(4):449-48.

Coffman, E. J. 2011. "Two Claims about Epistemic Propriety." Synthese.

Engel, P. (2008). 'In What Sense Is Knowledge the Norm of Assertion?', Grazer Philosophische Studien, 7r7(1), 45-59.

Engel, P. (2007). 'Belief and Normativity', Disputatio, 2(23), 1-25.

Engel, P. (2013). 'Doxastic Correctness'. Aristotelian Society Supplementary Volume, 87: 199-216. doi: 10.1111/j.1467-8349.2013.00226.x.

Gerken, M. (2013). 'Same, Same but Different: the Epistemic Norms of Assertion, Action and Practical Reasoning', Philosophical Studies, 120.

Green, A. (forthcoming). 'Deficient Testimony is Deficient Teamwork.' Episteme.

Hawthorne, J. (2004). Knowledge and Lotteries. Oxford: Oxford University Press.

Hawthorne, J. \& Stanley, J. (2008). 'Knowledge and Action.' Journal of Philosophy 105: 571-590.

Kvanvig, J. (2009) 'Assertion, Knowledge, and Lotteries', Williamson on Knowledge, eds Pritchard, D. \& Greenough, P. (Oxford: Oxford University Press, 2009) pp. 140-160.

Lackey, J. (2008). Learning From Words: Testimony as a Source of Knowledge. Oxford University Press.

Lackey, J. (2007). 'Norms of Assertion', Nous, 41(4), 594-626.

Lackey, J. (2012). 'Assertion and Isolated Secondhand Knowledge', in Jessica Brown and Herman Cappelen (eds.), Assertion (Oxford: Oxford 
University Press).

Lackey, J. (2013). 'Deficient Testimonial Knowledge,' In Tim Henning and David P. Schweikard (eds.), Knowledge, Virtue, and Action: Putting Epistemic Virtues to Work. New York: Routledge.

McKinnon, R.. (2012). "What I Learned in the Lunch Room about Assertion and Practical Reasoning." Logos and Episteme.

Milne, P. (2009). 'What is the Normative Role of Logic?', In Aristotelian Society Supplementary Volume (Vol. 83, No. 1, pp. 269-298). Blackwell Publishing Ltd.

Pagin, P. (2006). 'Against Normative Accounts of Assertion' (draft).

Pritchard, D. (2009). 'Knowledge, Understanding and Epistemic Value', Royal Institute of Philosophy Supplement 64, 19.

Shah, N., \&6 Velleman, J. D. (2005). 'Doxastic Deliberation' The Philosophical Review,114(4), 497-534.

Turri, J. (2014). 'Knowledge and Suberogatory Assertion,' Philosophical Studies 167: 557-567.

Williamson, T. (1996). 'Knowing and asserting', The Philosophical Review 105, 489-523.

Williamson, T (2000). Knowledge and its Limits, Oxford: Oxford University Press. 